\title{
Perencanaan Gedung Sinema Keluarga Di Kawasan Pulau Kumala Penekanan Pada Akustik Ruang
}

\author{
Bhanu Rizfa Hakim, ${ }^{1 *}$ Anna Rulia, ${ }^{2}$ Arif Indra Fahlafi ${ }^{3}$ \\ ${ }^{1,2}$ Program Studi Arsitektur, Jurusan Desain, Politeknik Negeri Samarinda, Samarinda, Indonesia
}

Received: September 2021

Acepted: October 2021

Published: October 2021

\begin{abstract}
The development of the cinema industry in the city of Samarinda and its surroundings has increased significantly. Currently, in Samarinda city itself, there are 5 places for famous cinema brands, namely XX1 Big Mall, XX1 Samarinda Square, XX1 SCP, Cinema 21 SCP, and most recently CGV Cinema Plaza Mulia. The development of the number of cinemas in East Kalimantan, especially Samarinda and its surroundings was triggered by the high attraction of the public for the world of cinema, ranging from adults to children. Therefore, this potential needs to be maximized with the planned construction of the Family Cinema Building in the Kumala Island area of the entertainment and game cluster, Tenggarong City, Kutai Kartanegara Regency, East Kalimantan. This great potential is supported by the strategic tourist area of Kumala Island and the absence of a well-known cinema brand in the city of Tenggarong. In addition, Kumala Island as a tourist island that needs to be managed and utilized by the Government and the Kutai Kartanegara Regency Tourism Office so that it becomes an attractive tourist attraction for the surrounding community and immigrants. The planning of the Family Cinema Building will be one of the best attractions for the community, because it is planned with the concept of a family cinema, providing 17 mini theater rooms, lounges, gardens and other facilities. So planning the development of this entertainment object needs to be done to maximize and restore the essence and image of Kumala Island as one of the best tourist destinations in East Kalimantan.
\end{abstract}

Key words: Planning, Family Cinema Potential, Kumala Island

\begin{abstract}
Abstrak
Perkembangan industri bioskop di kota Samarinda dan sekitarnya mengalami peningkatan yang cukup signifikan. Saat ini , di kota Samarinda sendiri terdapat 5 tempat brand bioskop terkenal, yaitu XX1 Big Mall, XX1 Samarinda Square, XX1 SCP, Cinema 21 SCP, dan yang terbaru CGV Cinema Plaza Mulia. Perkembangan jumlah bioskop di Kalimantan Timur, khususnya Samarinda dan sekitarnya dipicu dengan adanya daya tarik yang cukup tinggi dari masyarakat akan dunia perfilman, mulai dari kalangan dewasa hingga anak-anak. Oleh karena itu, potensi ini perlu dimaksimalkan dengan direncanakannya pembangunan Gedung Sinema Keluarga Di Kawasan Pulau Kumala cluster hiburan dan permainan , Kota Tenggarong, Kabupaten Kutai Kartanegara, Kalimantan Timur. Potensi yang besar ini didukung oleh kawasan wisata yang strategis Pulau Kumala dan belum adanya brand bioskop terkenal yang berada di kota Tenggarong. Di samping itu, Pulau Kumala sebagai pulau wisata yang perlu dikelola dan manfaatkan oleh Pemerintah dan Dinas Pariwisata Kabupaten Kutai Kartanegara sehingga menjadi objek wisata menarik bagi masyarakat sekitar maupun pendatang. Perencanaan Gedung Sinema Keluarga ini akan menjadi salah satu daya tarik terbaik bagi masyarakat, karena direncanakan dengan konsep bioskop keluarga, menyediakan 17 ruang teater mini, lounge, taman dan fasilitas lainnya. Maka perencanaan pembangunan objek hiburan ini perlu dilakukan untuk memaksimalkan serta mengembalikan esensi dan citra Pulau Kumala sebagai salah satu destinasi wisata terbaik di Kalimantan Timur.
\end{abstract}

Kata kunci: Perencanaan, Potensi Bioskop Keluarga, Pulau Kumala

\footnotetext{
* Corresponding author : bhanuhakim@polnes.ac.id
} 


\section{Pendahuluan}

Bioskop merupakan hiburan yang digemari oleh masyarakat pecinta film, dari kalangan dewasa 1 hingga anak kecil. Bioskop merupakan gedung pertunjukan untuk film. Dengan menggunakan layar yang lebar, bioskop mempunyai daya tarik tersendiri bagi masyarakat yang ingin menonton film, biasanya brand bioskop terdapat dalam sebuah mall dengan konsep desain yang sama. Bioskop banyak ditemukan hampir di setiap kota besar di Indonesia, termasuk salah satunya kota Samarinda, Kalimantan Timur.

Berdasarkan Kamus Besar Bahasa Indonesia, bioskop didefiniskan sebagai tempat untuk menonton pertunjukan film dengan menggunakan layar lebar. Dalam pertunjukan film citra gambar dalam gulungan film seluloid diproyeksikan ke layar berukuran berkali lipat lebih besar dengan menggunakan mesin proyektor.

Bioskop di Kalimantan Timur mengalami perkembangan yang cukup pesat, sebagai salah satu hiburan yang banyak digemari oleh masyarakat Kaltim, cukup mudah untuk menemukan brand - brand bioskop di dalam sebuah mall di Kaltim, Samarinda dan Balikpapan masih yang terdepan sebagai kota dengan tempat bioskop yang paling banyak, sehingga perlu untuk dilakukan pemerataan penyediaan tempat - tempat bioskop di kota - kota besar Kalimantan Timur lainnya [1].

Pulau Kumala merupakan salah satu objek wisata yang berada di Kota Tenggarong, Pulau yang dahulu merupakan kawasan kosong dan hampa ini dibangun menjadi kawasan wisata oleh Pemerintah Kab. Kutai Kartanegara. Adapun jumlah pengunjung Pulau Kumala berdasarkan data dari Dinas Pariwisata Kab.Kutai Kartanegara pada tahun baru 2020 sebanyak 10.318 pengunjung, terdiri dari 7.610 dewasa dan 2.708 anakanak. Data ini mengalami kenaikan dari tahun sebelumnya.

Potensi wisata yang terdapat pada Pulau Kumala harus dimanfaatkan dan dapat dinikmati oleh masyarakat, baik masyarakat Tenggarong maupun dari luar kota. Perencanaan Gedung Sinema Keluarga pada Cluster Hiburan dan Permainan di Pulau Kumala ini akan menambah antusiasme masyarakat sekitar dan menghidupkan kembali objek wisata Pulau Kumala, dengan mengusung konsep sinematik keluarga dan arsitektur modern kontemporer yang inovatif, sehingga menjadi sebuah destinasi wisata menarik di kawasan Pulau Kumala.

\section{Kerangka Teori}

\section{Pengertian Perencanaan}

Perencanaan adalah suatu tahapan dalam manajemen project yang mencoba meletakkan dasar tujuan dan sasaran sekaligus menyiapkan segala program teknis dan administratif agar dapat diimplementasikan.

\section{Pengertian Sinema}

Berdasarkan Kamus Besar Bahasa Indonesia, bioskop didefiniskan sebagai tempat untuk menonton pertunjukan film dengan menggunakan layar lebar. Dalam pertunjukan film citra gambar dalam gulungan film seluloid diproyeksikan ke layar berukuran berkali lipat lebih besar.

\section{Pengertian Akustik Ruang}

Prinsip dalam akustik interior adalah memperkuat atau mengarahkan bunyi yang berguna serta menghilangkan atau memperlemah bunyi yang tidak berguna untuk pendengaran manusia. Dengan demikian, mendesain interior ruang tertentu, harus disesuaikan dengan kebutuhan akustik dari aktivitas yang terjadi di dalamnya [2].

\section{Akustik Ruang}

Akustik adalah sebuah ilmu tentang tata suara, dan keseluruhan efek-efek yang ditimbulkan oleh suara tersebut terhadap para penikmatnya. Dalam arsitektur, cakupan akustik tersebut berkaitan secara langsung dengan pengondisian lingkungan dan tapak, estetika bentuk dari ruang atau bangunan, desain bangunan pelingkup ruang, bentuk-bentuk dan dimensi ruang (terutama konfigurasi ruang dalam/interior) [3].

\section{Audio Pendukung Akustik Bioskop}

Untuk mendapatkan pengalaman menonton yang mengesankan, di dalam ruangan teater harus menyediakan fasilitas audio pendukung yang memadai, tentunya pemasangan sound system yang tepat juga semakin bisa memberikan sensasi menonton. 
Salah satu merek penyedia sound system (sistem audio) untuk theatre paling terkenal adalah Dolby. Brand ini boleh dibilang cukup baik dan tidak pernah berhenti dalam meluncurkan teknologi terbaru khusus untuk kualitas suara yang semakin memuaskan pemakainya.

Terlepas dari merek sound system (sistem audio) di ruang bioskop, ada 3 konfigurasi speaker atau pengeras suara yang umumnya sering digunakan, antara lain 5.1, 7.1 dan 9.1. Salah satu yang apling sering digunakan adalah Dolby 7.1 saat menonton di ruangan bioskop di mal- mal, dan pada saat menonton akan terasa pula suara - suara yang berbeda-beda datang dari sekeliling ruangan bioskop. Ini adalah instalasi strategis yang mendukung pengalaman menonton sehingga semakin intens.

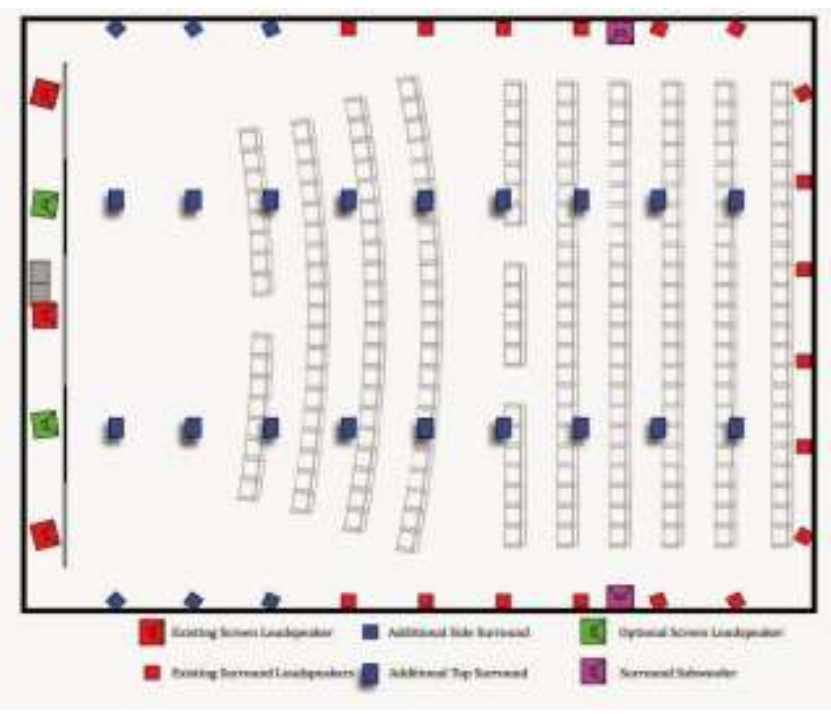

Gambar 1. Skema Instalasi Surround Sound Dolby Atmos

Selain intensitas dan surround sound yang semakin baik dengan penambahan speaker, pemilihan sound system juga berefek pada besar kecilnya ruangan theatre. Semakin tinggi sound system yang dipilih, berarti semakin banyak ruang untuk menampung speaker- speaker tersebut.

\section{Standarisasi Dimensi Ruang dan Elemen}

Standar bioskop diperlukan untuk membuat kenyamanan dalam menonton bioskop. Hal pertama yang merupakan standar bioskop adalah proyeksi. Menurut Kamus Besar Bahasa Indonesia (KBBI) [4], proyeksi adalah gambar suatu benda yang dimuat rata (mendatar) atau berupa garis pada bidang datar.

Lebar film $16 \mathrm{~mm}, 35 \mathrm{~mm}$, dan $70 \mathrm{~mm}$. Tengah sinar proyeksi harus tidak membias lebih dari $5^{\circ}$ horizontal dan pembias.
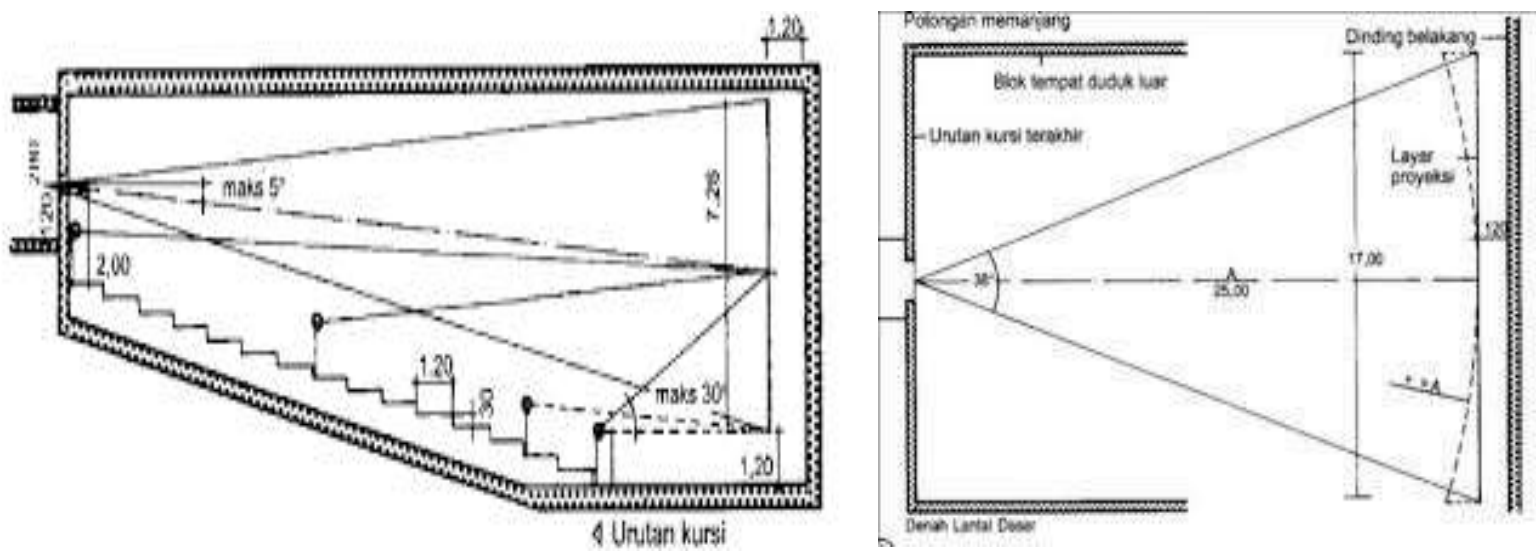

Gambar 2. Besaran Ruang Penonton Optimal 
Menurut Mediastika [2] dinding pada teater bioskop terbagi menjadi tiga area dengan penanganan persyaratan akustiknya masing-masing yaitu dinding pada bagian belakang layar proyeksi, dinding pada sisi kiri dan kanan penonton dan dinding pada bagian belakang penonton yang dekat dengan ruang proyektor.

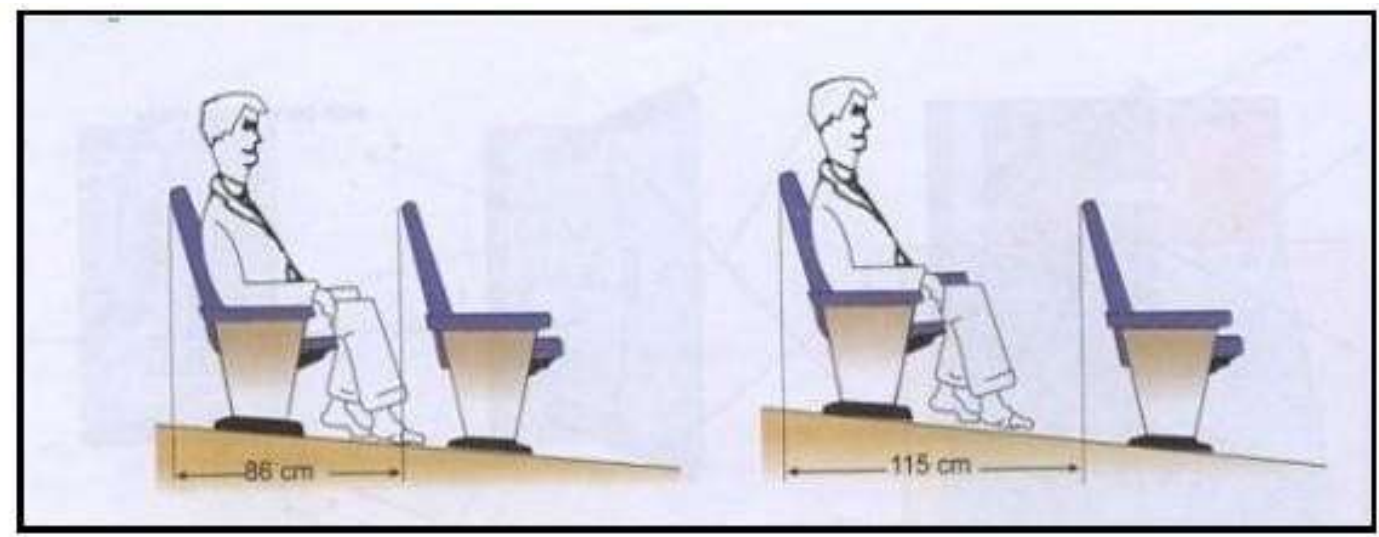

Gambar 3. Pengaturan Jarak Kursi Pada Bioskop

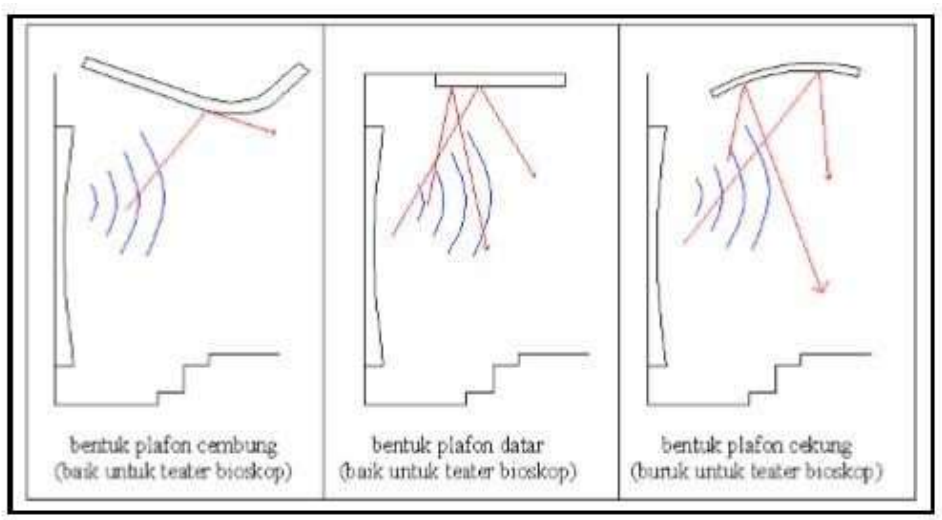

Gambar 4. Rekomendasi Bentuk Plafon Bioskop

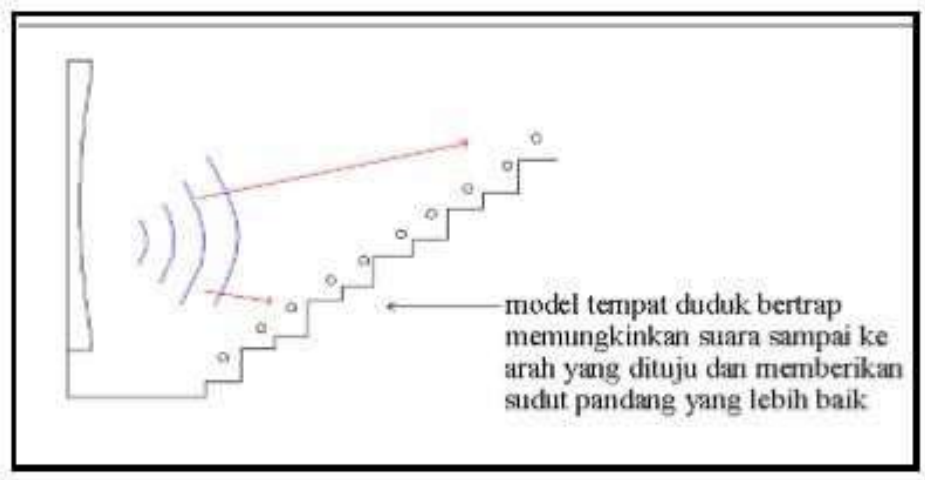

Gambar 5. Penyusunan Lantai Pada Bioskop

Beberapa model dari langit-langit dari ruangan di bioskop yaitu, pantulan bunyi pada langit-langit datar yang cenderung menimbulkan gema, langit-langit yang dimanfaatkan untuk memantulkan bunyi lebih terarah ke audiensi dan mengurangi gema, dan langit-langit yang dimanfaatkan untuk memantulkan bunyi secara baur agar bunyi memenuhi ruangan, bagus untuk ruangan musik. 


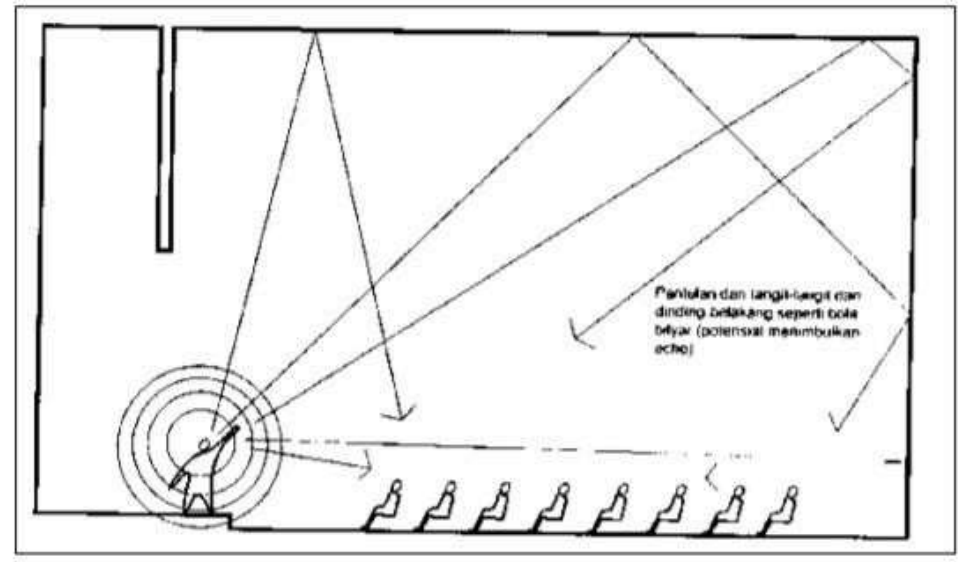

Gambar 6. Pantulan Bunyi Pada Langit-Langit Datar

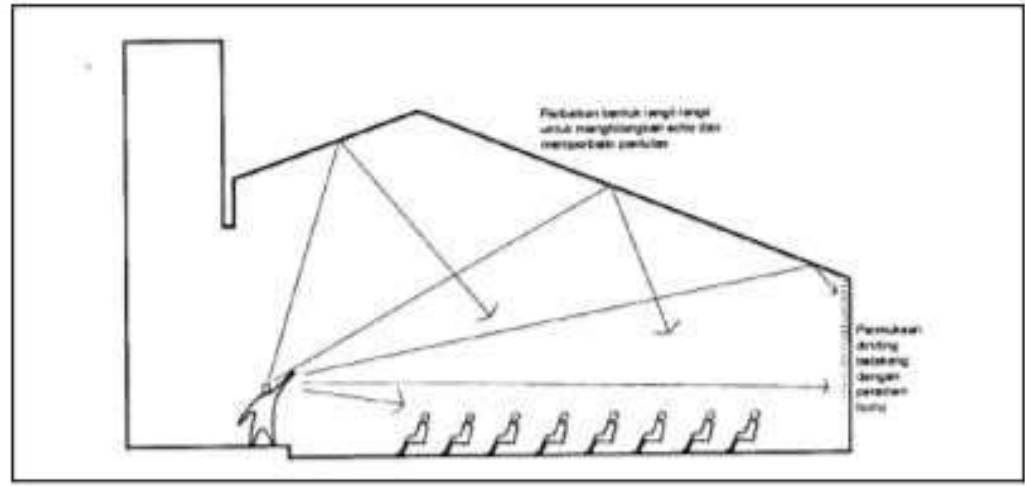

Gambar 7. Pantulan Yang Terarah Ke Audiensi

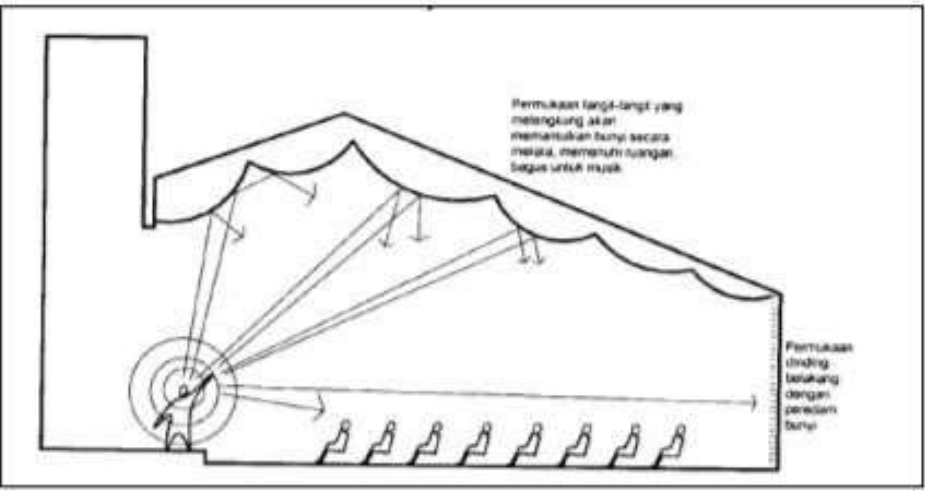

Gambar 8. Pantulan Yang Memantulkan Secara Baur

\section{Metode Perencanaan}

Dalam metode perencanaan Gedung Sinema Keluarga di Kawasan Pulau Kumala Tenggarong dengan penekanan pada akustik ruang, metode pengumpulan data baik itu data primer maupun data sekunder yang berhubungan dengan konsep perancangan kemudian diikuti dengan metode pengolahan data yang telah diperoleh yaitu : identifikasi masalah, pengumpulan data, analisi data, konsep, perancangan.

\section{Metode Pengolahan Data}

Dalam metode pengolahan data dilakukan langkah-langkah dalam sebagai berikut:

Membuat analisis peruangang, analisis tapak, analisi bangunan, analisis utilitas, membuat konsep perancangan yang meliputi konsep peruangan, tapak, bangunan, utilitas. 
Setelah analisis dan konsep terbuat maka langkah selanjutnya yaitu membuat transformasi desain sebelum mulai perancangan gambar kerja, kemudian membuat rencana anggaran biaua (RAB) dan rencana kerja dan syarat-syarat (RKS).

\section{Hasil Dan Pembahasan}

Dari hasil Perencaaan Gedung Sinema Keluarga Penekanan pada Akustik Ruang di Kawasan Pulau Kumala ini, dapat disimpulkan bahwa :

Konsep Perencaaan Gedung Sinema Keluarga Penekanan pada Akustik Ruang di Kawasan Pulau Kumala ini ditekankan pada akustik ruang, bertujuan untuk menciptakan ruang teater yang nyaman dan memberikan kualitas suara yang maksimal, dengan memperhatikan pencahayaan dan penghawaan buatan maupun alami, sehingga dapat maksimal memanfaatkan sumber energi. Didukung dengan penerapan konsep arsitektur kontemporer yang memberikan suasana berbeda dalam sebuah gedung bioskop modern.

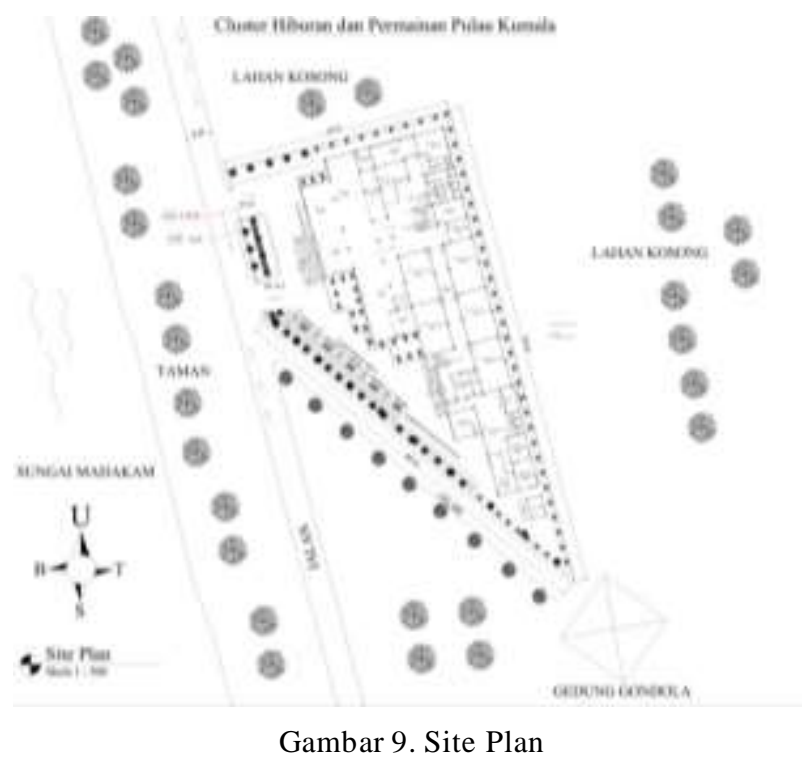

Site Plan pada tapak perencanaan gedung sinema keluarga, sistem sirkulasi pada site menggunakan ME in dan ME out.

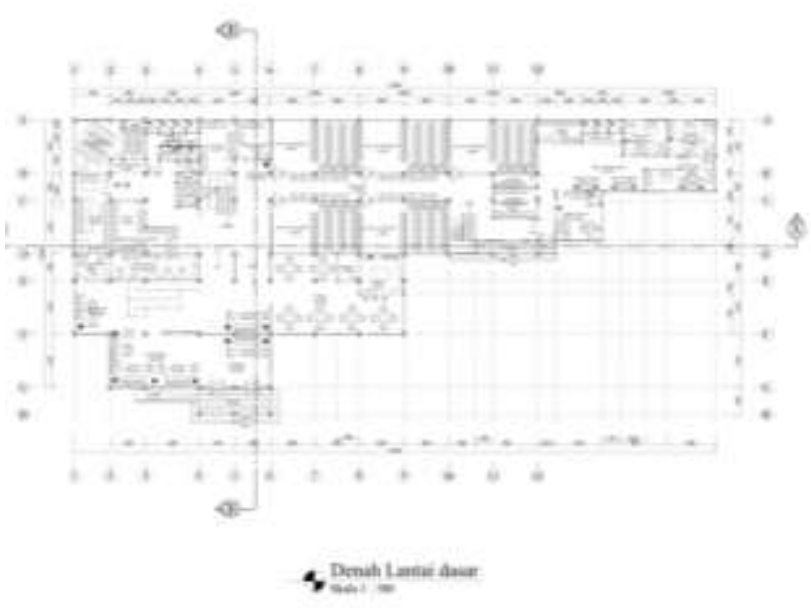

Gambar 10. Denah Lantai Dasar

Pada bagian lantai dasar terdapat lobby, lounge, area ticket, café, 5 ruang teater dan area karyawan di sebelah kanan bangunan. 


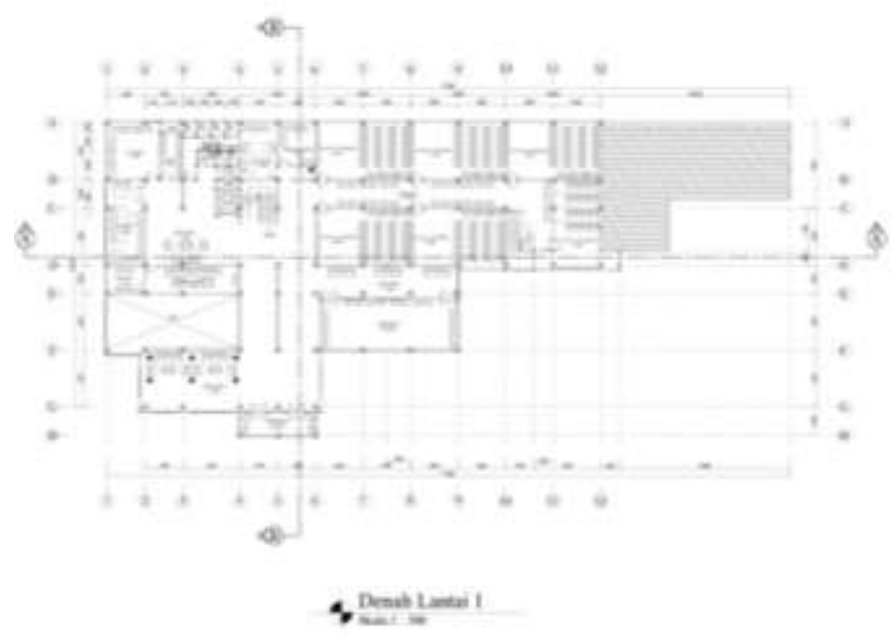

Gambar 11. Denah Lantai 1

Pada bagian lantai 1 terdapat 6 ruang teater, lounge yang cukup luas, dan 2 balkon untuk akses evakuasi dan tempat bersantai untuk pengunjung.

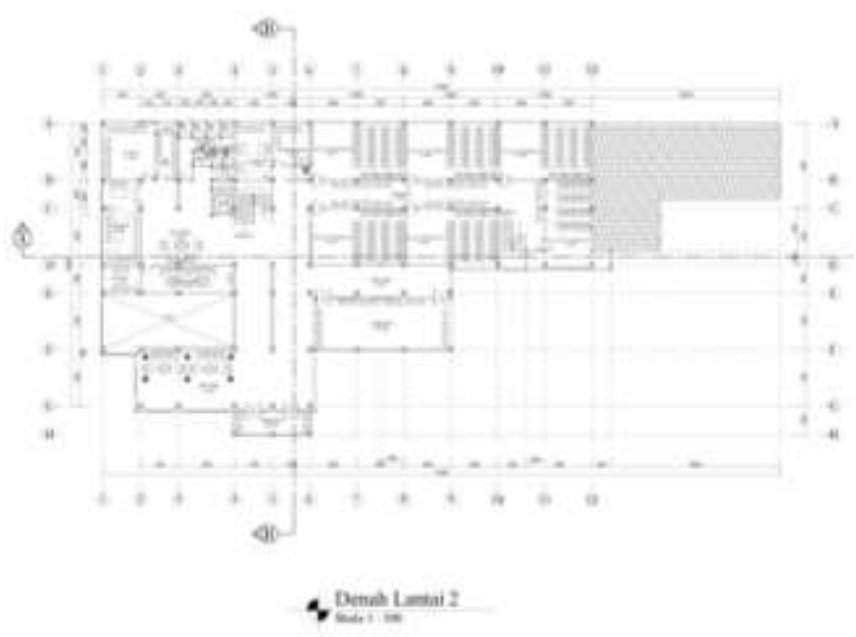

Gambar 12. Denah Lantai 2

Fasilitas pada lantai 2 sama seperti lantai 1, Pada bagian lantai 2 terdapat 6 ruang teater, lounge yang cukup luas, dan 2 balkon untuk akses evakuasi dan tempat bersantai untuk pengunjung. 
Bhanu Rizfa Hakim, Anna Rulia, Arif Indra Fahlafi

Perencanaan Gedung Sinema Keluarga Di Kawasan Pulau Kumala Penekanan Pada Akustik Ruang

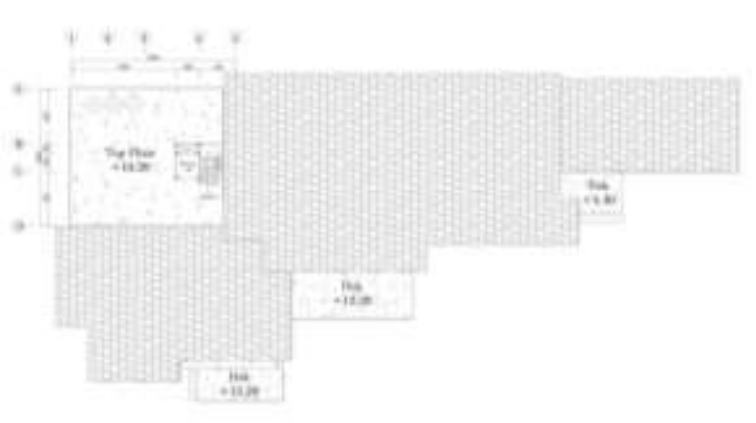

4 Denih Tip Flow

Gambar 13. Denah Top Floor

Pada top floor terdapat rumah lift dan ruang yang cukup luas untuk area tendon

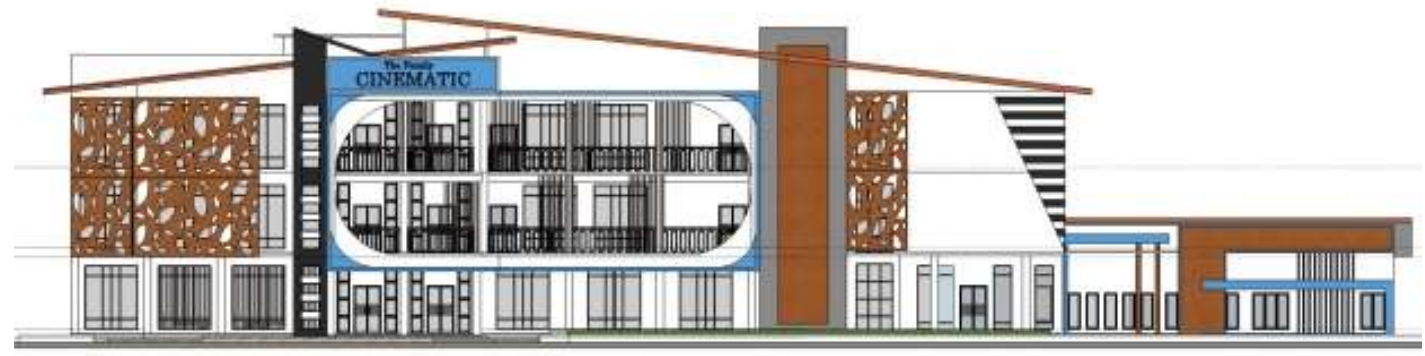

Gambar 14. Tampak Depan

Tampak depan bangunan dengan gaya arsitektur modern kontemporer, terdapat banyak bukaan yang pada fasad bangunan dan secondary skin untuk estetika bangunan dan mereduksi sinar matahari.

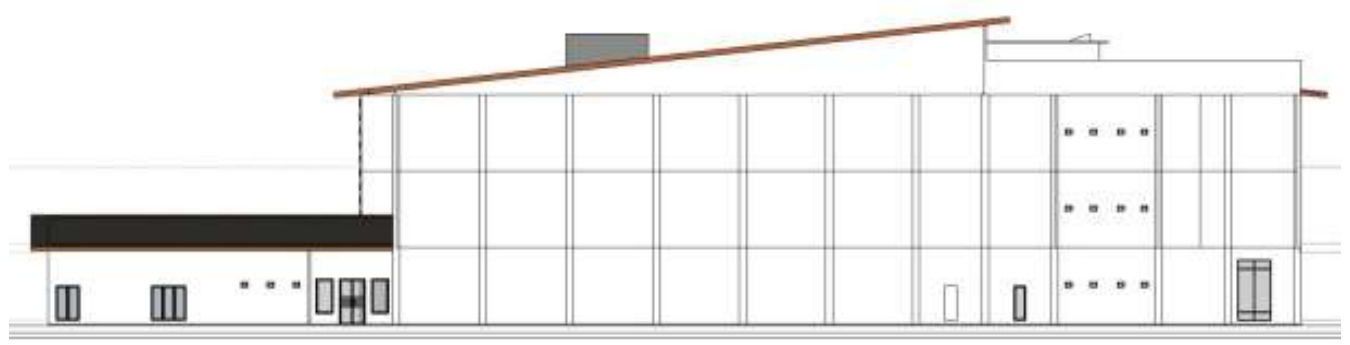

Gambar 15. Tampak Belakang

Tampak belakang bangunan gedung sinema keluarga, terlihat hanya beberapa ventilasi dan bukaan pada area staf. 


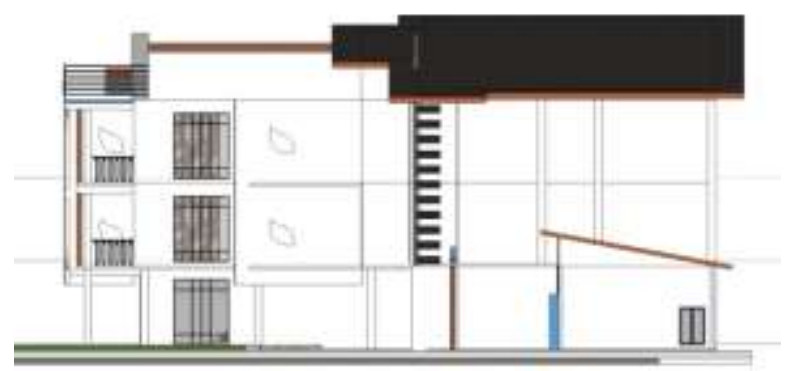

Gambar 16. Tampak Samping Kanan

Tampak samping kanan bangunan gedung sinema terdapat area gedung staf satu lantai.

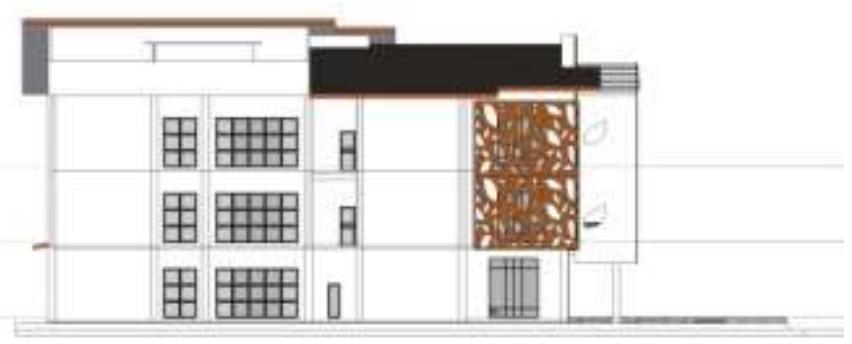

Gambar 17. Tampak Samping Kiri

Tampak samping kiri bangunan terdapat bukaan yang cukup lebar untuk memaksimalkan sinar matahari pada ruang pantry.

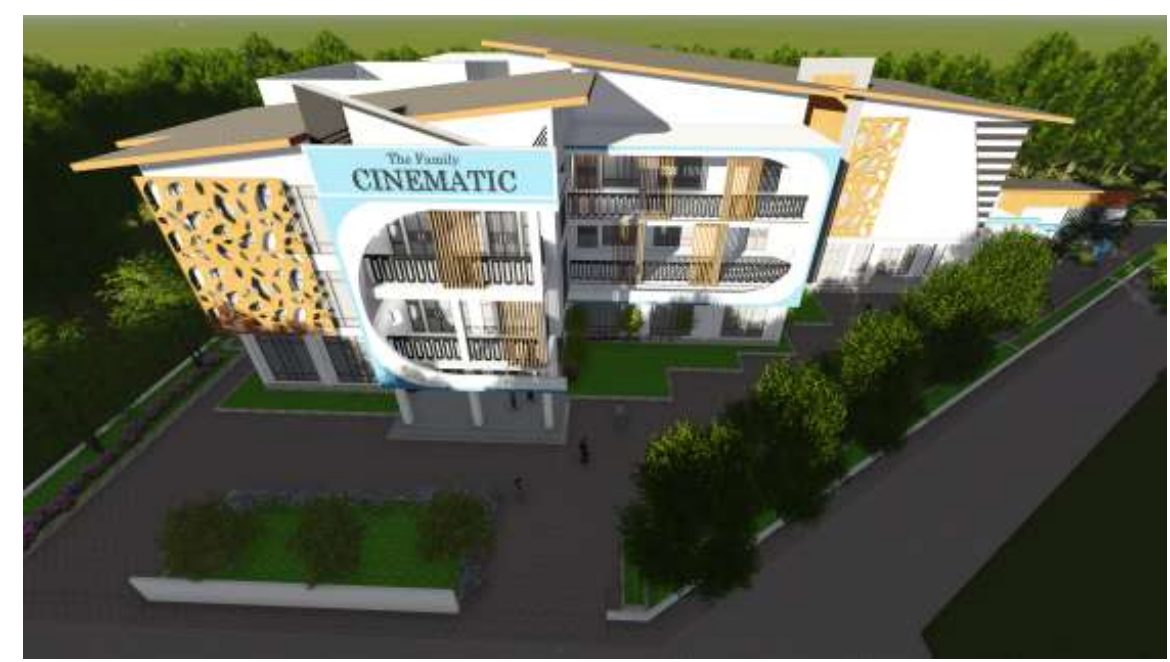

Gambar 18. Tampak Samping Kiri

Perspektif dari bangunan gedung sinema keluarga, terlihat dominasi papan nama bangunan dan secondary skin sebagai vocal point gedung. 


\section{Kesimpulan Dan Saran}

Kesimpulan

Gedung Sinema Keluarga merupakan sebuah perencanaan fasilitas untuk masyarakat dapat menikmati tayangan bioskop yang menjadi hiburan masa kini dengan mengusung konsep cinema keluarga. Konsep Perencaaan Gedung Sinema Keluarga Penekanan pada Akustik Ruang di Kawasan Pulau Kumala ini ditekankan pada akustik ruang, bertujuan untuk menciptakan ruang teater yang nyaman dan memberikan kualitas suara yang maksimal, dengan memperhatikan pencahayaan dan penghawaan buatan maupun alami, sehingga dapat maksimal memanfaatkan sumber energi. Didukung dengan penerapan konsep arsitektur kontemporer yang memberikan suasana berbeda dalam sebuah gedung bioskop modern.

\section{Saran}

Adapun saran dari penulis yaitu, pada perencanaan gedung sinema keluarga penekanan pada akustik ruang ini diharapkan dapat menjadi sarana dan contoh gedung bioskop dengan akustik ruang yang baik dan meningkatkan kualitas fasilitas dan pelayanan terhadap masyarakat yang berkunjung ke gedung sinema keluarga dapat merasakan kenyamanan hiburan bioskop dan menjadi destinasi wisata yang unggul. 
Jurnal Kreatif: Desain Produk Industri dan Arsitektur. Vol. 9 No. 2, Oktober 2021 pp. 146 - 156

\section{Daftar pustaka}

1. Hakim, B.R., 2020.

2. Mediastika, E.C., Akustika Bangunan. 2005, Yogyakarta: ANDI.

3. Sutanto, H., Prinsip-Prinsip Akustik Dalam Arsitektur. 2015, Yogyakarta: PT. Kanisius.

4. Kamus Besar Bahasa Indonesia. 1994, Jakarta: Balai Pustaka. 